\title{
Zoneamento ambiental do polo de desenvolvimento agroindustrial do Alto Piranhas, Estado da Paraíba
}

\section{Environmental zoning polo agro industry development of Alto Piranhas, Paraíba State}

\author{
Juciê de Sousa Almeida ${ }^{1}$; Jordana Medeiros da Costa ${ }^{2}$; Paulo Xavier Pamplona ${ }^{3}$; Patrício Borges Maracajá4; Wellington \\ Ferreira de Melo ${ }^{5}$
}

\begin{abstract}
Resumo: Este trabalho teve como objetivo zonear os níveis de deterioração ambiental na paisagem entre os anos de 2001 e 2012, adotando os critérios da ecodinâmica nos municípios que compõe o polo de desenvolvimento agroindustrial do Alto Piranhas. Foram realizadas análises envolvendo a dinâmica da paisagem e da vulnerabilidade ambiental. A metodologia utilizada na pesquisa foi baseada em localizações pontuais, que inclui o processo de selecionar e combinar, através de procedimento de álgebra de mapas disponíveis em um SIG, cada variável geográfica contém diferenciação espacial e a combinação entre elas promove a subdivisão do espaço geográfico em regiões equiproblemáticas. Tomando-se por base as superposições dos mapas geológico, geomorfológico e pedológico foi efetuado o mapa de zoneamento ambiental, com informações que permitiram identificar as condições do meio natural e suas aptidões. Esses fatores foram comparados entre si, conforme a importância atribuída a elas. Os resultados indicaram que as áreas centrais concentram as classes com maiores riscos ambientais, como as instáveis (risco ambiental entre 60 e 80\%), e as de instabilidade emergente (risco maior que 80 . Já nas áreas distribuídas em toda a área de estudo encontra-se as áreas com risco ambiental entre 40 e $60 \%$ (instabilidade moderada). Com base na análise, percebe-se que a área de estudo possui um tênue equilíbrio por estar localizado em ambiente semiárido que pode ser rompido com facilidade com a intensificação das atividades agroindustriais.
\end{abstract}

Palavras-chave: Desequilíbrio ambiental, dinâmica da paisagem, fragilidade ambiental, álgebra de mapas.

Abstract: This study aimed to zone the levels of environmental deterioration in the landscape between the years 2001 and 2012, adopting the criteria of ecodynamics municipalities that make up the hub of agro-industrial development of the Alto Piranhas. Analyzes involving the dynamics of landscape and environmental vulnerability were performed. The methodology used in this research was based on specific locations, including the process of selecting, combining, through map algebra available in a GIS procedure, each geographical variable contains spatial differentiation, and the combination between them promotes the geographical subdivision of space equiproblemáticas regions. Taking as a basis the superimposition of geological, geomorphological and pedological maps was made environmental zoning map, with information that allowed the identification of the conditions of the natural environment and their skills. These factors were compared according to the importance assigned to them. The results indicated that the central areas concentrate the classes with larger environmental hazards such as unstable (environmental risk between 60 and 80\%), and the emerging instability (greater than 80 risk. Already on distributed throughout the area of study areas located the areas with environmental risk between 40 and $60 \%$ (moderate unrest). Based on the analysis, it is noticed that the study area has a fine balance to be located in semiarid environment that can be broken easily with the intensification of agribusiness activities.

Key words: Environmental imbalance, landscape dynamics, environmental fragility, map algebra.

\footnotetext{
*Autor para correspondência

Recebido para publicação em 15/10/2015; aprovado em 20/12/2015

${ }^{1}$ Mestre em Sistemas Agroindustriais, FIP; juciesalmeida@gmail.com

${ }^{2}$ Inserir aqui Titulação, Instituição, E-mail

${ }^{3}$ Prof. D. Sc. da UFCG/CCTA/PPGSA - pxpamplona@ gmail.com

${ }^{4}$ Prof. D. Sc. da UFCG/CCTA/PPGSA - patriciomaracaja@ gmail.com

${ }^{5}$ Prof. MSc. da UFCG/CCJS - wellingtonabcd@ gmail.com
} 


\section{INTRODUÇÃO}

Existe uma crescente preocupação em associar as políticas de desenvolvimento socioeconômico com políticas de recuperação e manutenção da qualidade ambiental do espaço. Muitos são os casos de um notável crescimento econômico de uma região aliado a um desequilíbrio ambiental. Essa situação atinge muitas vezes níveis drásticos, chegando a impossibilitar a continuidade de atividades econômicas específicas. Com o advento de processos técnicos e científicos, que promoveram uma nova dinâmica de estruturação da paisagem, com indícios consideráveis de degradação ambiental, essa realidade pode ser mudada ou simplesmente adequada.

Os zoneamentos ambientais em geral têm como objetivo principal o ordenamento do território em áreas ou zonas homogêneas com características e potencialidades similares. No caso do zoneamento ambiental, esse ordenamento objetiva a delimitação de zonas com características e potencialidades ambientais semelhantes. A delimitação dessas zonas se dá pela análise dos aspectos ambientais de forma integrada, ou seja, são considerados os aspectos físicos aliados às informações socioeconômicas.

Umas das premissas deste trabalho é desenvolver zoneamento ambiental das áreas do polo baseado nos conceitos de fragilidade ambiental de Jurandir L. Ross (2004) e da ecodinâmica da paisagem de J. Tricart (1977; 1992), integrando estes métodos com técnicas de geoprocessamento. Tais resultados poderão ser aplicados na regularização do uso do território da área de estudo, o polo de desenvolvimento agroindustrial do Alto Piranhas. Em face das poucas alternativas de exploração competitiva no semiárido, essas áreas devem ser utilizadas por uma agricultura mais tecnificada, baseada, sobretudo, na fruticultura tropical, de modo a maximizar a produtividade, economicidade das explorações e estabilidade do empreendimento.

Sendo o polo do Alto Piranhas uma área de jurisdição de vários municípios, com intenso uso antrópico e com demanda considerável dos recursos naturais, assume particular importância a realização dessas pesquisas, contribuindo para o ordenamento das atividades, com o fim de preservar os recursos naturais. A presente pesquisa teve como objetivo zonear os níveis de deterioração ambiental na paisagem entre os anos de 2001 e 2012, adotando os critérios da ecodinâmica nos municípios que compõe o polo de desenvolvimento agroindustrial do Alto Piranhas.

\section{MATERIAL E MÉTODOS}

\section{Área de estudo}

A área de estudo é o Polo de Desenvolvimento Agroindustrial do Alto Piranhas, localizado do Sertão do Estrado da Paraíba, entre as coordenadas $6^{\circ} 23$ ' 32 " a $7^{\circ} 5^{\text {, }}$ $30^{\prime}$ 'de Latitude Sul, $37^{\circ} 30^{\prime} 55^{\prime \prime}$ a $38^{\circ} 42^{\prime}$ 54" de Longitude Oeste, possui uma área de $4.200,9 \mathrm{Km}^{2}$. A área possui um total de 12 municípios, entre estão: Cajazeiras, Marizópolis, Sousa, São José do Rio do Peixe, Lastro, Aparecida, São Domingos, São Bentinho, São Francisco, Cajazeirinhas, Pombal e Condado (Figura 1).

Figura 1: Localização polo da região do Alto Piranhas no estado da Paraíba, Brasil.

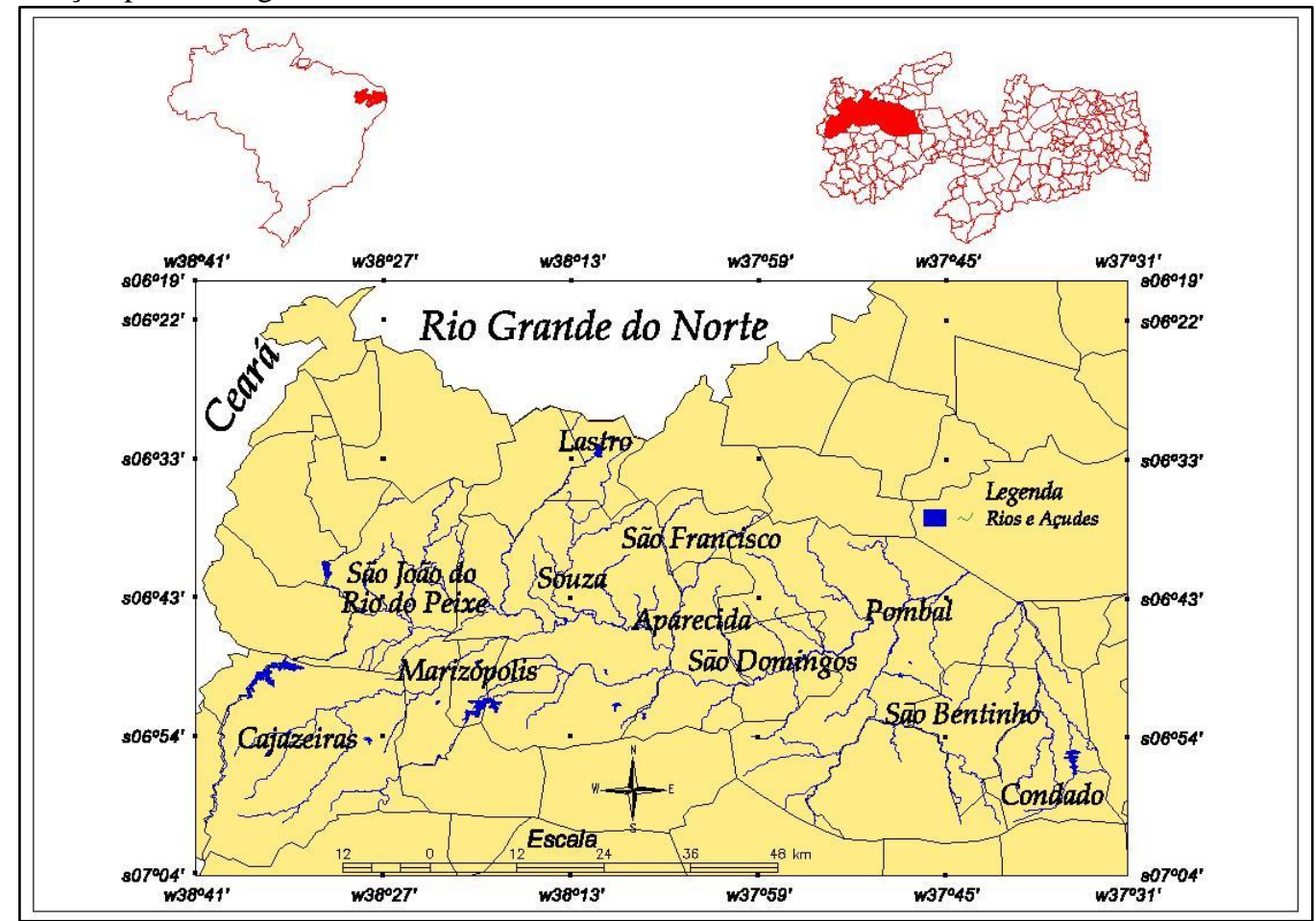

Fonte: Autor (2015)

O conhecimento do tipo climático da região fornece indicativos sobre as condições médias de pluviosidades e temperatura. Essas características são uma das mais importantes informações para aplicar as atividades de planejamento, pois exerce grande influência na dinâmica ambiental. $\mathrm{Na}$ área de estudo, a posição geográfica e a proximidade com o Planalto da Borborema e a distância do 
Oceano Atlântico, confere condições importantes nas condições climáticas da área.

A partir dos 12 postos pluviométricos, observa-se para o período de 2001 - 2012, uma média de 469,8 mm/ano, sendo o Sudoeste de Pombal a localidade com menor precipitação (200 - 400 mm/ano) e o Sul de Sousa a com maior (1001 - 1200 mm/ano). As precipitações são maiores no interior da área de estudo, ficando em torno de 541,5 $\mathrm{mm} / \mathrm{ano}$, em 2002, e 398,1 mm/ano em 2012, diminuindo gradualmente em direção ao centro, nas menores altitudes (Figura 2)

Figura 2: Pluviosidade média da região do Alto Piranhas no estado da Paraíba, Brasil

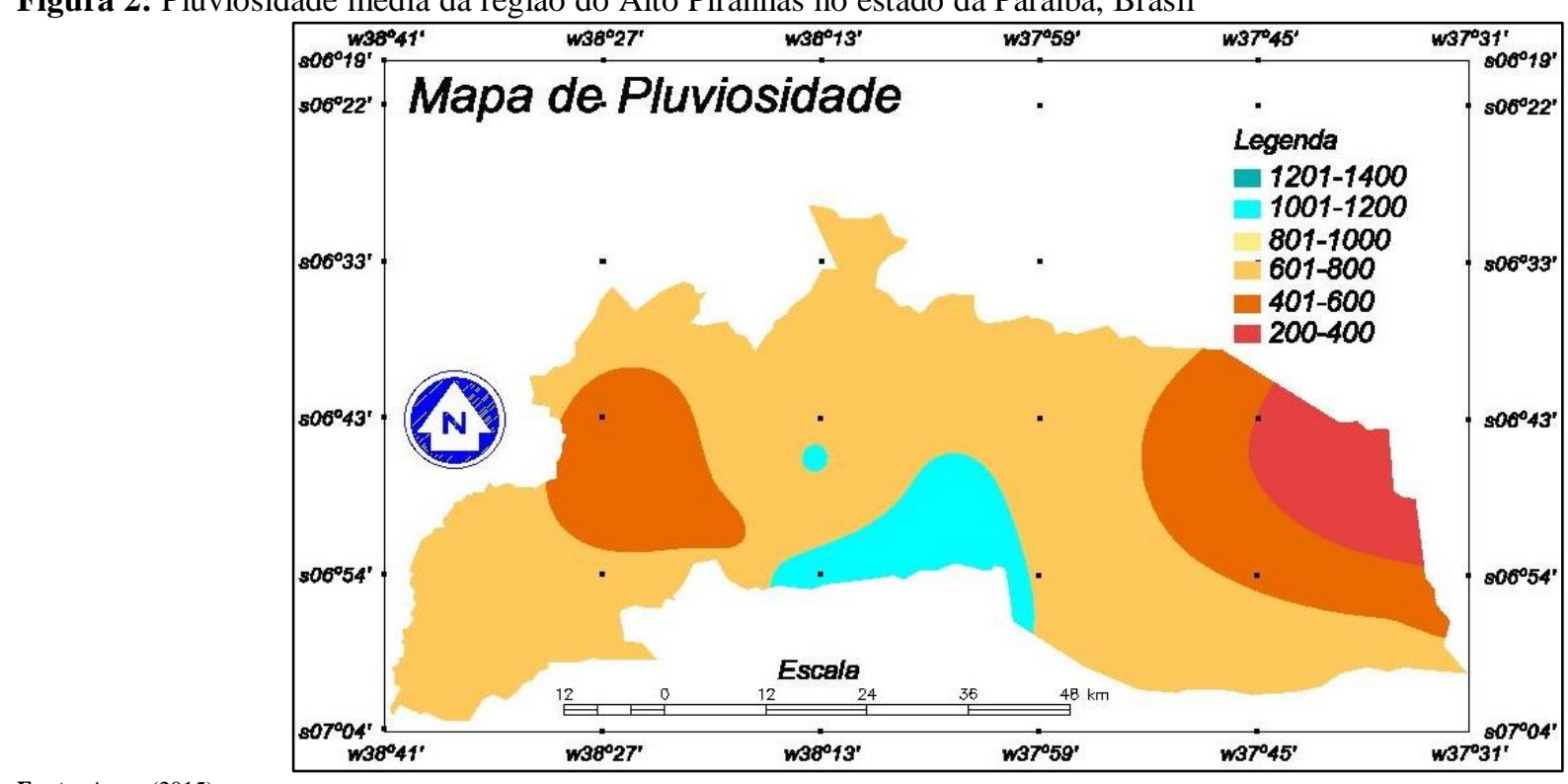

Fonte: Autor (2015)

A geologia e a geomorfologia da área de estudo é composta por rochas metagranitóides, gnaisses da Suíte Poço da Cruz (Grupo Orós), que se apresentam como o Planalto e a Depressão Sertaneja de superfície Tabular, no sentido Norte, acompanhando os municípios que limitam a Paraíba e o Ceará (Figura 3).

Segundo Medeiros et al. (2005), o Complexo Caicó (PP3бpcg, PP3Ypc) abrange a porção sul e oeste, localizado na porção oriental do maciço mediano do Rio Piranhas, constituído por rochas metassedimentares, gnaisses, xistos e calcários com biotita gnaisses indiferenciados (PP2cai, PP2caim, PP2Ycal). A Suíte Intrusiva Itaporanga (NP3 Y 2it) são formadas por Granitos, com ocorrência de dioritos e calcialinos e quartzo sienitos de Brejo dos Santos.

A área ainda apresenta os Depósitos aluvionares e de terraços (N34a), que se refere-se à formações de sedimentos quartenários, que ocorrem associados aos principais rios da região. Essas formações são recoberta basicamente por depósitos de cascalho, argila e areias terciárias e quartenários. A Formação Rio do Peixe (K1sz) e a Formação Rio Piranhas (K1rp), representa a porção sedimentar do Grupo Rio do Peixe, e sua ocorrência restringe-se a bacia do Rio do Peixe e Piranhas.

Figura 3: Geologia da região do Alto Piranhas no estado da Paraíba, Brasil

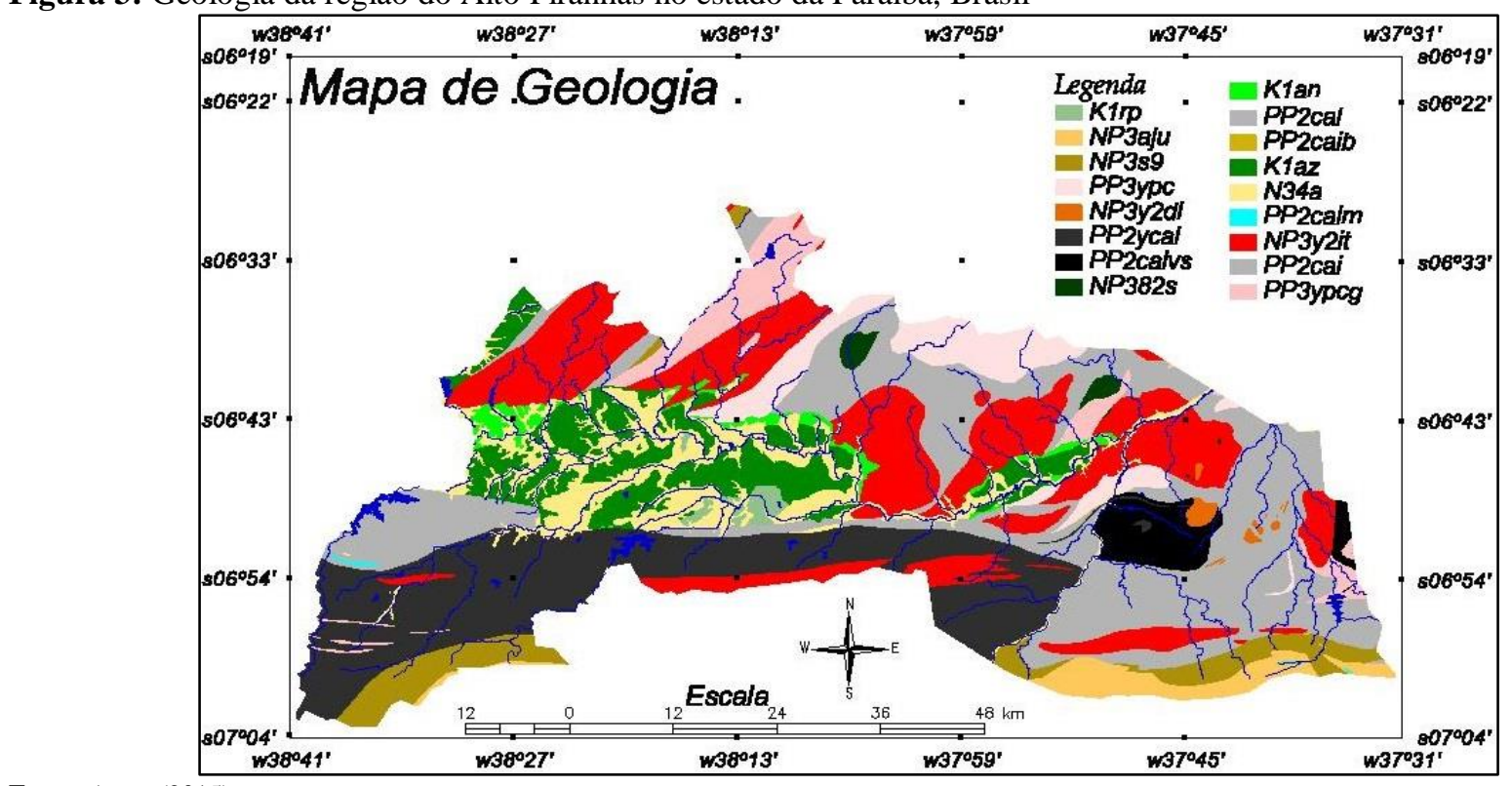

Fonte: Autor (2015) 
O enquadramento fitogeográfico do Alto Piranhas, segundo IBGE (2012b), corresponde principalmente às Caatingas Estépicas Arborizadas e Florestadas. Tipicamente estruturada em dois estratos: um superior, com predominância de espécies decíduas, pouco adensadas por grossos troncos, esgalhados, espinhoso; e um estrato inferior descontínuo. A agricultura é divididas em culturas cíclicas e permanentes, são usados vários sistemas de preparação do solo, como o cultivo convencional, gradagem, cultivo mínimo, plantio direto na palha. A pecuária é praticada com efetivo bovinos, equinos, caprinos, ovinos, suínos e aves. Desenvolvidas extensivamente em pastagens naturais, plantadas e degradadas. A Tabela 1 e a Figura 4 apresentam os dados de uso e cobertura da terra do Alto Piranhas para o ano de 2012. O relevo da área de estudo é bastante ondulado nas unidades compostas pelas serras, também apresenta informações escarpadas nas regiões ao norte e ao sul, as superfícies mais suaves e suaves ondulados se concentram no interior da área de trabalho.

Tabela1: Uso e cobertura da terra da região do Alto Piranhas no estado da Paraíba, Brasil.

\begin{tabular}{lccc}
\hline Uso da terra & Área $(\mathrm{Km})$ & Área (Hectares) & $(\%)$ Total \\
\hline Água & 31,3 & $3.126,9$ & 0,7 \\
Agricultura Irrigada & 229,9 & $22.991,6$ & 5,5 \\
Caatinga Estépica Florestada & 906,1 & $90.609,8$ & 21,5 \\
Caatinga Estépica Arborizada & $1.511,0$ & $151.098,6$ & 35,8 \\
Afloramento Rochoso & 10,5 & $1.045,5$ & 0,2 \\
Zona Urbana & 378,1 & $37.812,0$ & 9,1 \\
Agropecuária & $1.148,7$ & $114.872,9$ & 27,2 \\
\hline
\end{tabular}

Figura 4: Uso e Ocupação do Solo do da região do Alto Piranhas no estado da Paraíba, Brasil.

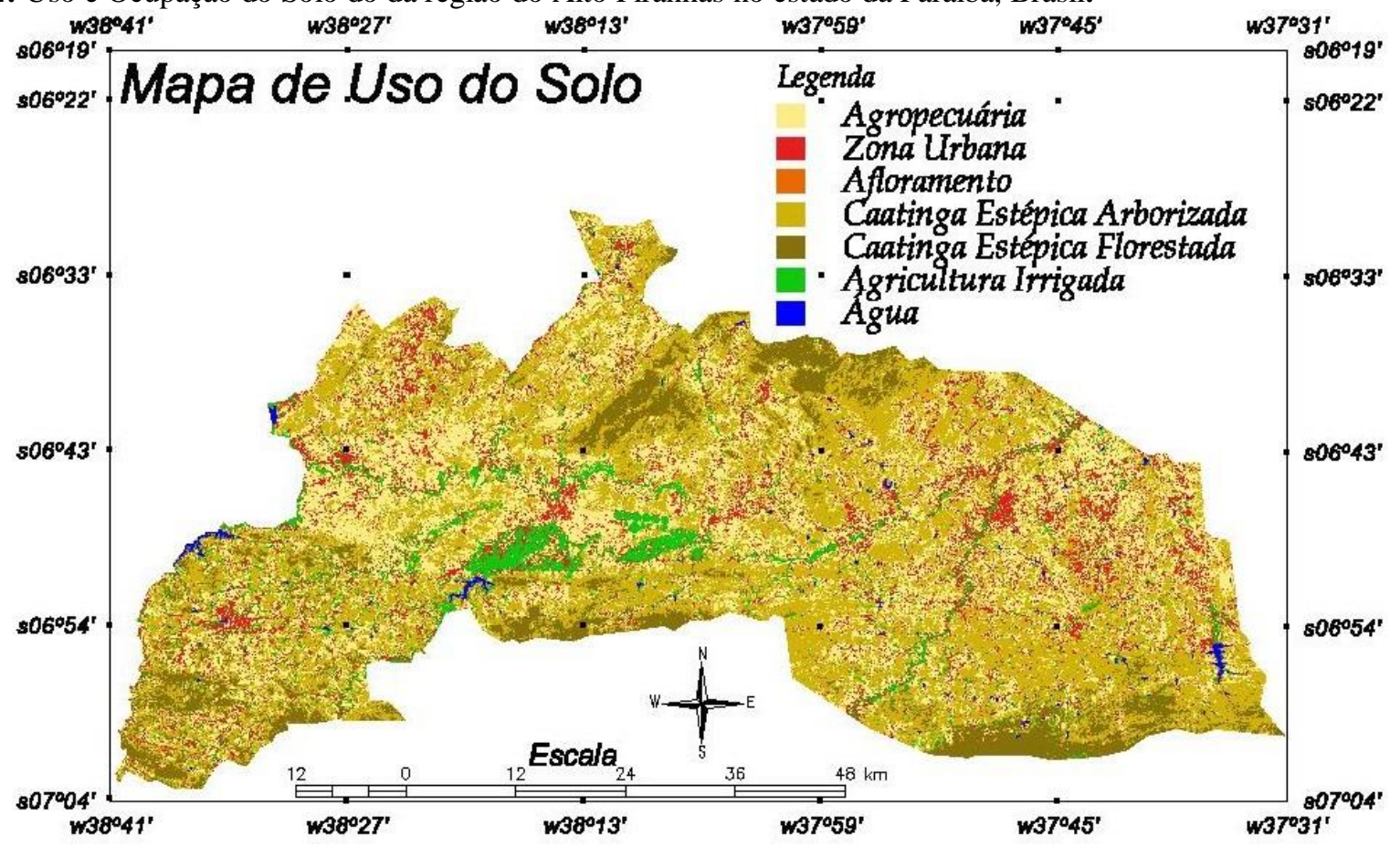

Fonte: Autor (2015)

\section{Métodos Utilizados}

Foi utilizado o método baseado em localizações pontuais, que inclui o processo de selecionar e combinar, através de procedimento de álgebra de mapas disponíveis em um SIG, cada variável geográfica contém diferenciação espacial e a combinação entre elas promove a subdivisão do espaço geográfico em regiões equiproblemáticas.

Tomando-se por base as superposições dos mapas geológico, geomorfológico e pedológico foi efetuado o mapa das condições ambientais, com informações que permitiram identificar as condições do meio natural e suas aptidões. Esses fatores foram comparados entre si, conforme a importância atribuída a elas.
Após o desenvolvimento do mapa de Zoneamento Ambiental, foi superposto o Mapa de Uso da Terra, cuja as informações permitiram distinguir cinco unidades territoriais baseados na ecodinâmica da paisagem de diferentes características que vão determinar normas específicas para cada área em relação à ocupação do solo e ao manejo dos recursos naturais. Essas unidades consistem em Áreas Estáveis; Áreas com Estabilidade Moderada; Áreas com Instabilidade Moderada; Áreas Instáveis; Áreas com Instabilidade Emergente. Com apoio nessas determinações, definiu-se o zoneamento, que para elaboração utilizou-se o Spring 5.2, utilizando operações de álgebra de mapas, por 
meio do ambiente de programação em LEGAL. O mapa foi confeccionado na escala de 1:480.000.

\section{RESULTADOS E DISCUSSÃO}

A integração dos planos de informações temáticas feitas a partir de operações algébricas entre os diversos mapas temáticos possibilita estabelecer os parâmetros para a obtenção do mapa de zoneamento ambiental da área de estudo. Os ambientes inicialmente em equilíbrio dinâmico, ao avaliar os níveis de fragilidade natural, desenvolvido por Tricart (1977) e Ross (1994), que segundo uma concepção analisa o meio ambiente sob a ótica da Teoria dos Sistemas das Unidades Ecodinâmicas.

Os valores foram ponderados em geo-campos numéricos procuram indicar de forma mais fiel possível, os graus de vulnerabilidade dos ambientes analisados, considerando suas influências antrópicas, que podem distinguir ou influenciar a maior ou menor vulnerabilidade da área. Primeiramente fazemos o estabelecimento de pesos para os temas de Uso e Cobertura do Solo/Vegetação, fatores físicos da área, como litologia, geomorfologia, precipitação e pedologia (Tabela 2). Esses fatores são responsáveis pela morfoestruturação e morfoesculturação da área.

Tabela2: Importância das classes de declividade nos processos erosivo.

\begin{tabular}{c|c}
\hline Categorias & Classes de Declividade \\
\hline Muito fraco & Até $7 \%$ \\
Fraco & De 7 a $10 \%$ \\
Médio & De 10 a $20 \%$ \\
Forte & De 20 a $30 \%$ \\
Muito forte & Acima de $30 \%$ \\
\hline
\end{tabular}

Fonte: Ross (1994).

As classes de erodibilidade dos solos, de acordo com Ross (1994), considerando o processo de escoamento superficial, podem ser agrupados da seguintes forma na Tabela 3.

Os processos erosivos sobre as formações geológicas são apresentados na Tabela 4, considerando o grau de agregação das partículas e a resistência aos processos erosivos.

Tabela3: Importância dos tipos de solos na ocorrência de processos erosivos.

\begin{tabular}{cc}
\hline Categorias & Classes de Solos \\
\hline Muito fraco & Vertisolo \\
Fraco & Podzólico Vermelho Amarelo Eutrófico \\
Médio & Solonetz Solodizado \\
Forte & Solos Aluviais \\
Muito forte & Litólico Distrófico, Litólico Eutrófico, Bruno não Cálcico \\
\hline
\end{tabular}

Fonte: Ross (1994).

Tabela4: Importância das formações geológicas no processo erosivo.

\begin{tabular}{cc}
\hline Categorias & Classes de formações geológicas \\
\hline Muito fraco & Suíte Poço da cruz, Formação Jucurutu \\
Fraco & Complexo Caicó \\
Médio & Suíte Intrusiva Itaporanga, Suíte Intrusiva Dona Inês \\
Forte & Suíte Intrusiva São João do Sabugi, Formação Serra do Quintos \\
Muito forte & Formação Rio Piranhas, Antenor Navarro, Sousa e Depósitos aluvionares e de terraços \\
\hline
\end{tabular}

Fonte: Ross (1994).

Esse tipo de análise espacial representa valores, em que os dados são transformados para espaços de [ $\left[\begin{array}{lll}0 & \ldots & 3\end{array}\right]$, e processados por combinação numérica. $\mathrm{O}$ principal objetivo no estabelecimento do zoneamento ambiental baseado na ecodinâmica do meio natural corresponde à elaboração de um cenário preservacionista, que permita selecionar áreas com potenciais e necessidades de recuperação. No zoneamento ambiental, observado na Figura 5, a fragilidade ambiental varia de áreas "estáveis" até áreas com "instabilidade emergente", em uma escala de $\left[\begin{array}{lll}0 & \ldots & 100 \%\end{array}\right]$ de risco ambiental. A Tabela 5 apresenta as classes de fragilidade ambiental, bom como o seu risco ambiental.

Tabela5: Zoneamento ambiental do polo de desenvolvimento agroindustrial do Alto Piranhas.

\begin{tabular}{cccc}
\hline Classe de Zoneamento Ambiental & Risco Ambiental & Hectares & $(\%)$ \\
\hline Estável & Até 20\% & 731,9 & 0,3 \\
Estabilidade Moderada & Entre 20 a 40\% & $21.489,6$ & 5,1 \\
Instabilidade Moderada & Entre 40 a 60\% & $243.304,3$ & 57,9 \\
Instável & Entre 60 a 80\% & $142.531,3$ & 22,9 \\
Instabilidade Emergente & Acima de 80\% & $11.933,7$ & 2,8 \\
Total & --- & $419.990,8$ & 100 \\
\hline
\end{tabular}


Figura 5: Zoneamento ambiental do polo de desenvolvimento agroindustrial do Alto Piranhas

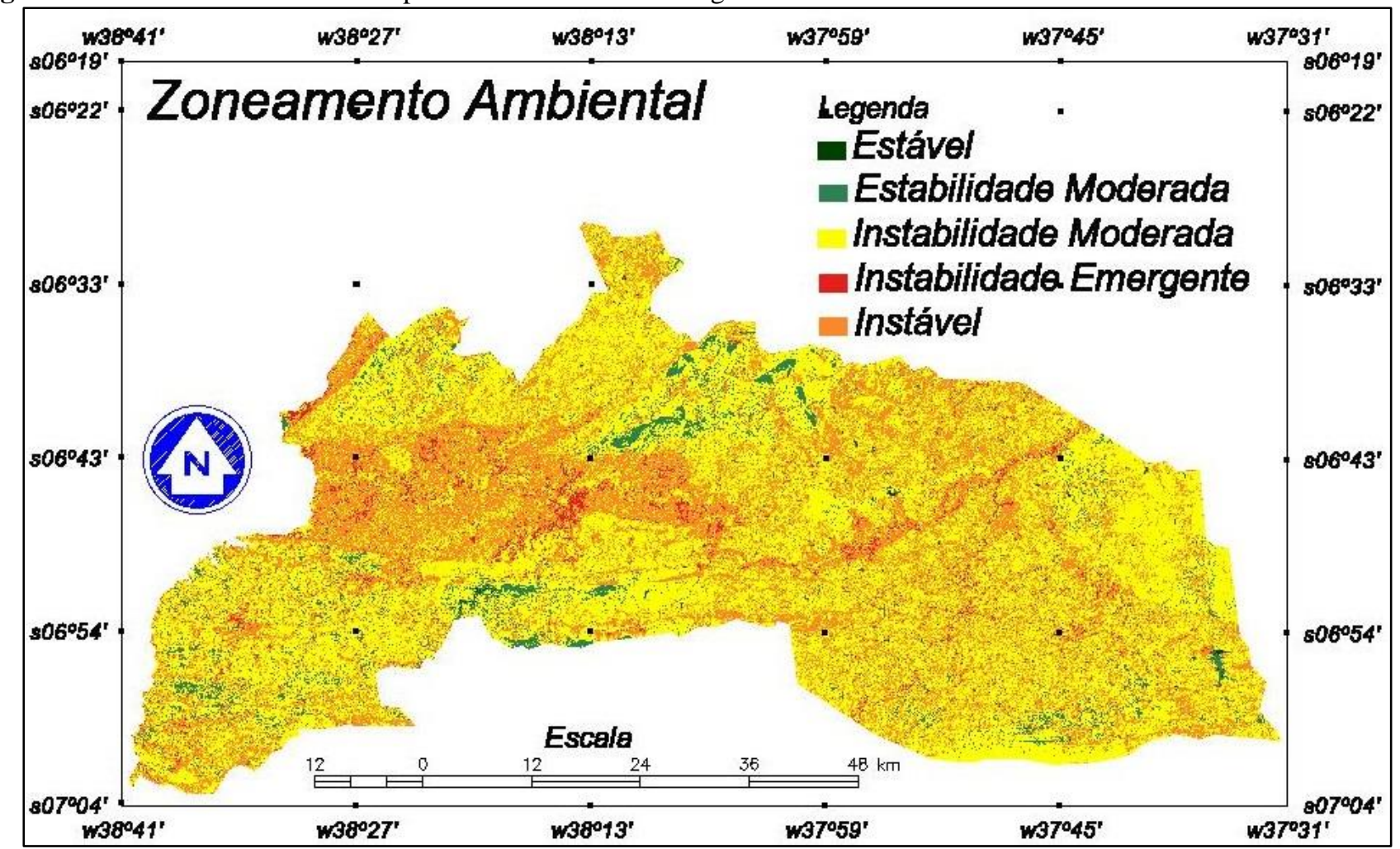

Fonte: Autor (2015)

A partir do zoneamento, pode-se estabelecer a adequação da ocupação e as normas para a proteção das áreas com os maiores riscos ambientais. As áreas que apresentam elevada instabilidade, necessitam de maiores proteções, o que pode ser obtido com recuperação de áreas desmatadas ou agrícolas que se enquadram nessa classificação. De uma forma geral, define que as áreas que apresentam as maiores instabilidades são ocupadas por atividades agrícolas nas maiores declividades, pois esta combinação define os processos de instabilidade e fragilidade aos processos erosivos. Em contrapartida, as áreas estáveis apresentam baixa cobertura vegetal e altas declividades.

Cita-se aqui também a influência do tipo de solo, agravante dos processos erosivos, pois estão associados aos solos litólicos e bruno não cálcicos que criam condições favoráveis a instalação de erosão laminar, devido principalmente da baixa profundidade e elevada permeabilidade destes tipos de solos. As áreas estáveis (risco ambiental de até 20\%), ocupam 731,9 hectares do polo do Alto Piranhas, ocorrendo principalmente no interior da área de estudo. As áreas de estabilidade moderada (risco ambiental entre 20 e 40\%) também ocorrem em toda uma área de 21.489,6 hectares. Nas áreas centrais ocorrem classes com maiores riscos ambientais, como as instáveis (risco ambiental entre 60 e $80 \%$ ), com 142.531,3 hectares, e as de instabilidade emergente (risco maior que $80 \%$ ), com $11.933,7$ hectares. Já nas áreas distribuídas em toda a área de estudo encontra-se as áreas com risco ambiental entre 40 e $60 \%$ (instabilidade moderada), que ocupam uma área de 243.304,3 hectares.

\section{CONCLUSÕES}

O processo de zoneamento ambiental a partir da fragilidade ambiental permite organizar e avaliar a ocupação humana, bem como a intensidade de exploração. A metodologia de zoneamento ambiental empregando álgebra de mapas se mostrou eficiente para o ambiente semiárido. A relação direta existente entre o uso e ocupação do solo e a fragilidade ambiental no polo de desenvolvimento agroindustrial do Alto Piranhas, se mostrou como um indicativo para a análise ambiental dessa área, pois forneceu subsídios para determinar o nível de ocupação e a capacidade do ambiente de absorver as atividades agroindustriais.

Com base na análise e na determinação dos graus de vulnerabilidade ambiental do Alto Piranhas, percebe-se que a área de estudo possui um tênue equilíbrio por estar localizado em ambiente semiárido que pode ser rompido com facilidade com a intensificação das atividades agroindustriais. Portanto, é necessário que as ações humanas sobre essa área sejam ordenadas, planejada e gerenciada, de uma forma que os recursos naturais não possam ser exauridos e os solos não sejam esgotados.

\section{REFERÊNCIAS}

BARBOSA, C. C. F. Álgebra de mapas e suas aplicações em sensoriamento remoto e geoprocessamento. Dissertação (Dissertação de Mestrado) - Instituto Nacional de Pesquisas Espaciais. São José dos Campos-SP, Agosto 1997.

IBGE. Manual Técnico da Vegetação Brasileira. 2. ed. Rio de Janeiro-RJ. 2012. 91p.

MEDEIROS, V. C.; AMARAL, C. A.; ROCHA, D. E. G. A.; SANTOS, R. B. Geologia da Paraíba, Rio Grande do Norte e Ceará. 2005. Programa Geologia do Brasil - Sousa. Folha SB.24-Z-A. 1 mapa, color. $66 \mathrm{~cm}$ x 108cm. Escala 1:250.000.

ROSS, J. L. S. Análise empírica da fragilidade dos ambientes naturais e antropizados. Revista do Departamento de Geografia. n.8, p.63-74. 1994. 
SPORL, C.; ROSS, J. L. S. Análise comparativa da TRICART, J.; KIEWIETDEJONGE, C. Ecogeography and fragilidade ambiental com aplicação de três modelos. rural management: A contribuition to the international GEOUSP - Espaço e Tempo, 2004. n. 15, p. 39-49, 2004. geosphere-biosphere programme. Essex. Longman Scientific TRICART, J. Ecodinâmica. [S.1.]: IBGE-SUPREN, 1977. e Technical. 1992. 1992. 